\title{
CORRESPONDENCE
}

\section{Scientists should cut waste too}

Your call for scientists to rally for continued federal funding (Nature 470, 305; 2011) places no responsibility on them to reduce the \$1.3-trillion US budget deficit.

As many scientists depend on taxpayers' money for research, they have an obligation to reduce waste and inefficiency and to work within their means. Funding agencies cannot and should not continue to do business as usual.

For example, the National Institutes of Health (NIH) imposes a salary cap of $\$ 199,700$ for scientists; most other federal agencies do not. The indirect costs' claimed by academic institutions range from $55 \%$ to $60 \%$ of the total grant budget. This implies that the taxpayer will pay $\$ 199,700$ for an NIHfunded radiologist but $\$ 398,571$ if the post were funded by another agency. Also, 55-60 cents of every research dollar will be spent on administrative and facilities costs, even though buildings and utilities have been paid for many times over.

Unlike companies, non-profit academic institutions deliver a paltry return on taxpayers' investments. In 2010, after spending nearly $\$ 3.1$ billion of taxpayers' money on intramural research, the NIH received \$91.6 million in royalties and was issued with 134 patents. By contrast, in 2009 IBM spent $\$ 6.5$ billion on research and development, generated $\$ 15.1$ billion in revenue and was issued with 4,914 patents. Matthew Kumar Mayo Clinic, Rochester, Minnesota, USA. mkumar@mayo.edu

\section{Anthropology: it can be interdisciplinary}

Adam Kuper and Jonathan Marks's gloomy portrait of integrative, big-question research in anthropology (Nature 470, 166-168; 2011) does not square with the large body of literature that covers areas such as behavioural ecology, cultural evolution, cognitive anthropology, gender studies, cross-cultural economics, moral psychology and environmental change. Publishing this work in high-impact general science and focused interdisciplinary journals ensures wide attention beyond the discipline.

The Evolutionary Anthropology Society was created to cut across traditional anthropological divides. It has some 350 members drawn from biological, cultural and archaeological specialities. Other interdisciplinary scholarly associations are The Human Behavior and Evolution Society, the European Human Behaviour and Evolution Association, and the Society for Anthropological Sciences. Each has hundreds of members active in the kind of research the authors claim is scarce or lacking. Productive interdisciplinary centres, such as the Centre for the Evolution of Cultural Diversity based at University College London, also catalyse innovative research that integrates biological, cultural and archaeological perspectives.

We feel that a genuinely interdisciplinary field of human diversity is emerging, synthesizing ideas and data from the social and behavioural sciences with theory and modelling techniques from evolutionary biology and game theory. Unlike Kuper and Marks, we see ample evidence that this work features in current debates about cognition, altruism, economic behaviour and environmental degradation (see, for example, M. Borgerhoff Mulder et al. Science 326, 682-688; 2009).

Eric Alden Smith on behalf of 30 co-signatories ${ }^{*}$, University of Washington, Seattle, USA. easmith@u.washington.edu
Michael Gurven University of California, Santa Barbara, USA Monique Borgerhoff Mulder University of California, Davis, USA. ${ }^{*} A$ full list of signatories is available online at http://dx.doi. org/10.1038/471448b.

\section{Anthropology: follow field primatologists}

Field primatology is one area of anthropology in which a classical cross-disciplinary approach is thriving (Nature 470, 166-168; 2011).

Field primatologists search the archaeological record of tool-using primates to gain insight into their cultures and traditions. Similarly, researchers of primate communication have set up a linguistic framework to investigate its intricacies in the context of the evolution of human language and music.

Like Jane Goodall and Birute Galdikas, whose studies on the great apes could read as ethnographies of a human group, field primatologists embrace long-term participant observation, a hallmark of social anthropology.

With the decline of natural forests, primate populations are nearly all intimately linked with their human neighbours. Field primatologists study their interactions, balancing the need for primate conservation with the cultural practices of the humans on whom the animals depend.

They advise on issues such as bushmeat hunting, the pet trade and the evolution of diseases that affect both human and non-human primates. They join cultural anthropologists and local people in examining data on past distributions and recent local extinctions of non-human primates and other animals.

In short, field primatology is successfully retaining and expanding the spirit of anthropology.
K. Anne-Isola Nekaris, Vincent Nijman Oxford Brookes University, Oxford, UK. vnijman@brookes.ac.uk Laurie R. Godfrey University of Massachusetts, Amherst, USA.

\section{Intolerance: UK chief scientist responds}

Andy Stirling and Brian Wynne (Nature 471, 305; 2011) call respectively for a democratic approach to scepticism and for recognition that scientific evidence often forms only part of complex decisions. I agree with them on both counts.

Of course it is true that advancement is attained through criticism, scepticism and debate. But my point was that there can sometimes be a thin line between healthy scepticism and a cynical approach that ignores or distorts inconvenient evidence.

Where significant consensus exists on an issue, this has not always been made obvious; also, tokenistic opposing views can be presented in a way that exaggerates their support.

Clearly, the role of scientific evidence in decision-making must be considered in the wider political and social context. However, I make no apology for demanding that the fundamental evidence and weight of consensus in such cases is set out in a proper and fair way.

John Beddington Chief Scientific Adviser to HM Government, Government Office for Science, London, UK. mpst.beddington@bis.gsi.gov.uk

\section{Negative results are published}

Jonathan Schooler argues in favour of an open-access database of negative results (Nature 470, 437; 2011). But publishing such results in scientific journals is 